\title{
Weld residual stress effects on fatigue crack growth behaviour of aluminium alloy 2024-T351
}

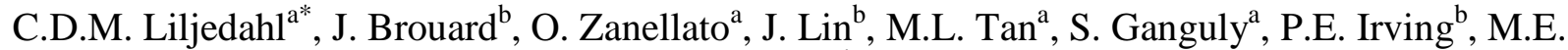 \\ Fitzpatrick $^{\mathrm{a}}, \mathrm{X}$. Zhang ${ }^{\mathrm{b}}, \mathrm{L}$. Edwards ${ }^{\mathrm{a}, \mathrm{c}}$ \\ ${ }^{a}$ Department of Materials Engineering, Faculty of Technology, The Open University, Walton \\ Hall, Milton Keynes MK7 6AA, UK \\ ${ }^{\mathrm{b}}$ Cranfield University, Bedfordshire MK43 0AL, UK \\ ${ }^{c}$ Institute of Materials Engineering, Australian Nuclear Science and Technology Organisation, \\ PMB1, Menai, NSW 2234, Australia
}

\begin{abstract}
The interaction between residual stress and fatigue crack growth rate has been investigated in middle tension and compact tension specimens machined from a variable polarity plasma arc welded aluminium alloy 2024-T3 plate. The specimens were tested at three levels of applied constant stress intensity factor range. Crack closure was continuously monitored using an eddy current transducer and the residual stresses were measured with neutron diffraction. The effect of the residual stresses on the fatigue crack behaviour was modelled for both specimen geometries using two approaches: a crack closure approach where the effective stress intensity factor was computed; and a residual stress approach where the effect of the residual stresses on the stress ratio was considered. Good correlation between the experimental results and the predictions were found for the effective stress intensity factor approach at a high stress intensity factor range whereas the residual stress approach yielded good predictions at low and moderate stress intensity factor ranges. In particular, the residual stresses accelerated the fatigue crack growth rate in the middle tension specimen whereas they decelerated the growth rate in the compact tension sample, demonstrating the importance of accurately evaluating the residual stresses in welded specimens which will be used to produce damage tolerance design data.
\end{abstract}

Keywords: Damage tolerance; Fatigue crack growth behavior; Crack closure; Residual stress; Eigenstrain

\section{INTRODUCTION}

Present innovations in aircraft manufacture include the creation of integral structures via manufacturing processes such as welding, replacing traditional riveting techniques [1] and permitting modular pre-fabrication of large integral sections of aircraft prior to final assembly. This can potentially reduce the cost and the weight of the final product. An inherent inconvenience is however the residual stress field caused by the welding process, which significantly influences the fatigue life of the structure $[2,3]$. The weld residual stresses must hence firstly be determined and their effect on fatigue crack growth rate (FCGR) accurately modelled if damage tolerant structures are to be optimally designed [4]. 
In previous research [5], the changes in fatigue crack closure as the crack traversed the weld was directly measured for specimens loaded at a constant stress intensity factor range $(\Delta K)$. The effective stress intensity factor range $\left(\Delta K_{\text {eff }}\right)$ was then computed from the acquired data. Recent studies of weld residual stresses and their redistribution arising from fatigue crack growth $[6,7$, 8] have also been performed. In these later studies the stresses were directly measured using neutron diffraction. Good correlation between the experimental data and the prediction of the residual stress re-distribtuion was found and the residual stress intensity factors $\left(K_{\text {resid }}\right)$ could henceforth be computed [8]. This was then used to calculate values of the effective stress intensity factor ratio $\left(R_{\text {eff }}\right)$. In the first approach the effect of the residual stresses on the fatigue crack growth were predicted with a $\Delta K_{\text {eff }}$ approach [5] where the $\Delta K$ when the crack is open is computed and in the latter with an $R_{\text {eff }}$ methodology [8] where the actual R-ratio is determined by taking the residual stresses into account. In this study the two approaches are compared and the benefits and shortcomings of the two methods in the prediction of the fatigue crack growth behaviour in a weld residual stress field of high magnitude are discussed. The predictions in the previous works $[5,8]$ were only carried out for one constant $\Delta K$; here the work is extended to three constant stress intensity factor ranges and results from an additional eigenstrain approach for the residual stress evolution prediction are presented.

\section{EXPERIMENTAL PROCEDURES}

\subsection{Specimens}

Single pass autogenous Variable Polarity Plasma Arc (VPPA) welding was used to manufacture 2024 aluminium plates measuring $500 \times 500 \mathrm{~mm}^{2}$. After welding, the plate was skimmed down to a thickness of $7 \mathrm{~mm}$. The plates were welded with the weld direction parallel to the plate longitudinal orientation. The middle tension $(\mathrm{M}(\mathrm{T}))$ specimens were machined with the dimensions and orientation shown in Figure 1. The compact tension $(\mathrm{C}(\mathrm{T})$ ) samples (Figure 1) were then sectioned from the $\mathrm{M}(\mathrm{T})$ specimen using electro-discharge machining (EDM).

\subsection{Fatigue loading and crack growth measurement}

Samples were subjected to Mode I fatigue loading at constant $\Delta K$ and $R$-ratio $\left(K_{\max } / K_{\min }\right)$ of 0.1 . Fatigue crack growth rates were measured for the $\mathrm{M}(\mathrm{T})$ specimen at constant $\Delta K$ values of 6,11 and $15 \mathrm{MPa} \sqrt{\mathrm{m}}$. The $\mathrm{C}(\mathrm{T})$ specimens were tested at $\Delta K$ values of $11 \mathrm{MPa} \sqrt{\mathrm{m}}, 13 \mathrm{MPa} \sqrt{\mathrm{m}}_{\mathrm{m}}$ and 15 $\mathrm{MPa} \sqrt{ } \mathrm{m}$. The crack growth was measured with the potential drop method. Further details of the experimental set-up can be found elsewhere [5].

\subsection{Crack closure measurements}

The crack opening load was constantly monitored with an eddy current transducer located at the crack mouth of the specimens. Further details of the experimental set-up can be found elsewhere [5].

\subsection{Residual stress measurements}

Neutron diffraction is an established non-destructive technique to determine stresses within metallic structures [4]. The measurements were carried out on the ENGIN-X diffractometer [9], which is based at the pulsed neutron source ISIS, of the Rutherford Appleton Laboratory in the 
UK. ENGIN-X has two detector banks at $\pm 90^{\circ}$ to the incident beam, which allows for measurements in two directions at the same time. Details of the stress measurement experiments are published elsewhere [6,7]. The gauge volume used was $2 \times 8 \times 2 \mathrm{~mm}^{3}$, with the longer dimension being oriented so as to encompass the thickness direction of the plate. Plane stress conditions were assumed and hence, only the components in the longitudinal and transverse directions were needed to be determined for computation of the residual stresses.

In-situ fatigue loading was carried out using a $100 \mathrm{kN}$ INSTRON servo-hydraulic test machine mounted on the diffractometer. The crack was propagated by applying a constant $\Delta K$ of 6 $\mathrm{MPa} \sqrt{\mathrm{m}}$ for the $\mathrm{M}(\mathrm{T})$ specimen and $17 \mathrm{MPa} \sqrt{\mathrm{m}}$ for the $\mathrm{C}(\mathrm{T})$ specimen at an $R$-ratio of 0.1 . Measurements were taken as the crack grew from the weld centre (Figure 1) until a half crack length of $25 \mathrm{~mm}$ was reached for the $\mathrm{M}(\mathrm{T})$ specimen and $44.5 \mathrm{~mm}$ for the $\mathrm{C}(\mathrm{T})$ specimen.

\subsection{Micro-structural hardness profile}

The micro-structural hardness profile was measured across the weld and the parent material with a Vickers indenter.

\section{MODELLING PROCEDURES}

\subsection{Residual stress evolution modelling}

The commercial code ABAQUS (standard version 6.5) was used for all the FEA (finite element analysis) modelling. The plate was thin compared to the width and the gauge volume extended through the whole thickness, and plane stress conditions were therefore assumed. Plane stress, 8 noded elements (CPS8) with full integration were used throughout the modelling presented in this paper. The smallest elements along the crack plane were $0.125 \mathrm{~mm}^{2}$. For the $M(T)$ specimen only a quarter of the sample was modelled due to the double symmetry, and half the sample was modelled for the $\mathrm{C}(\mathrm{T})$ specimen. An analytical surface and contact elements were assigned along the symmetry lines to avoid surface overlap.

Two approaches were employed to introduce the measured initial residual stresses in the FE models. In the first approach the residual stress field was introduced directly by using the SIGINI FORTRAN subroutine [10]. This approach for modelling the evolution of the residual stresses is further explained elsewhere [6,7].

The second approach used here was the eigenstrain approach [11]. Eigenstrain $\left(\varepsilon^{*}\right)$ is a nonuniform inelastic strain which causes elastic strains and hence stresses. Where the residual stresses are known throughout the whole component, then $\varepsilon^{*}$ can be determined from the following relation directly:

$$
\varepsilon^{*}=-C_{i j k l}^{-1} \sigma_{k l}^{r e s}
$$

where $C$ is the elastic constants tensor and $\sigma^{r e s}$ are the measured residual stresses.

The stress distribution away from the notch was measured in the $\mathrm{M}(\mathrm{T})$ specimen before it was fatigued. This stress distribution was assumed to represent the distribution throughout the uncracked specimen (i.e. assuming that the welded plate was continuously processed). In this case for a continuously processed body with $2 \mathrm{D}$ symmetry only one eigenstrain component in the longitudinal direction will contribute to the residual stresses [12] as the other components satisfy 
the compatibility equation. The transverse stress will also be small in the un-cracked component. The eigenstrain was hence computed as follows:

$$
\varepsilon_{11}^{*}(y)=-\frac{\sigma_{11}^{\text {res }}(x)}{E}
$$

where $E$ is the Young's modulus for the material. The eigenstrain field was introduced into the FEA model using a pseudo anisotropic thermal strain.

In the first analysis step the stresses were allowed to equilibrate, simulating the residual stresses in the $\mathrm{M}(\mathrm{T})$ specimen.

Crack extension was modelled by removing the boundary conditions along the symmetry line. The residual stresses in the $\mathrm{C}(\mathrm{T})$ specimen were predicted from the initial stress or eigenstrain distribution in the $\mathrm{M}(\mathrm{T})$ specimen, and simulating the stress re-distribution when the specimen was sectioned from the $\mathrm{M}(\mathrm{T})$ sample.

In order to be able to compare predictions with the experiment results, the stresses were averaged over the measured gauge volume. The stresses averaged over the gauge volume converged readily despite the stress concentration at the crack tip [6,7].

\subsection{The effective stress intensity factor range and $\boldsymbol{R}$-ratio}

There are two different approaches that are often used to account for residual stresses in prediction of their effect on fatigue crack growth rates. These are the effective stress intensity factor range ( $\left.\Delta K_{\text {eff }}\right)$ method approach first introduced by Elber [13], and superposition [14]. The stress intensity factors in the superposition approach were computed from the FEA model using the $J$-Integral approach [15].

In the effective stress intensity factor approach ( $\left.\Delta K_{\text {eff }}\right)$, the crack opening stress intensity factor $\left(K_{\mathrm{op}}\right)$ is measured and the SIF (stress intensity factor) range at which crack is open and can grow ( $\left.\Delta K_{\mathrm{eff}}\right)$ is computed as follows:

$$
\Delta K_{\text {eff }}=K_{\text {applied }} / \max -K_{o p}
$$

Superposition involves computation of the effect of the residual stresses on the 'actual' elastic stress intensity range at the crack tip (i.e. the residual stress intensity factor can be added to the applied stresses intensity factor). For the $\mathrm{C}(\mathrm{T})$ specimen, strict superposition was not valid due to non-linear contact conditions between the crack faces [8]. Hence the stress intensity factor was calculated at both $P_{\max }$ and $P_{\min }$ for this specimen. The stress intensity range $(\Delta K)$ and stress ratio $(R)$ was then computed as:

$$
\begin{gathered}
\Delta K=K_{\max }-K_{\min }, \quad R=\frac{K_{\min }}{K_{\max }}, \quad K_{\min } \geq 0 \\
\Delta K=K_{\max }, \quad R=0, \quad K_{\min }<0
\end{gathered}
$$

Further details can be found elsewhere [5,8].

\subsection{Prediction of the fatigue crack growth rates}

In the crack closure approach (equation 3) closure-free fatigue crack growth data $(R=0.7)$ was used to predict the effect of the residual stresses via experimental measurements of $K_{\text {op }}$ (equations $3)$. 
The crack growth rate in the residual stress approach was predicted by changes in $R$-ratio caused by the varying $K_{\text {resid }}$ and calculated using the residual stress (equations 4 and 5).

The material data necessary for the 2024-T351 alloy was obtained from the AFGROW database [16]. The data is available in the form of fitted constants to the NASGRO equation which effectively is an empirical Paris type relation in a sigmoid form:

$$
\frac{d a}{d N}=\left[C\left(\frac{1-f}{1-R}\right) \Delta K\right]^{n} \frac{\left(1-\frac{\Delta K_{t h}}{\Delta K}\right)^{p}}{\left(1-\frac{K_{\max }}{K_{\text {crit }}}\right)^{q}}
$$

where $C, n, p, q$ and $f$ are empirical material parameters, $\Delta K_{\text {th }}$ is the threshold stress intensity factor, $K_{\max }$ is the stress intensity factor at the maximum load and $K_{\text {crit }}$ is the critical stress intensity factor which relates to the thickness of the specimen. More details can be found elsewhere [16].

\section{RESULTS AND DISCUSSION}

The fatigue crack growth rates (FCGR) for the M(T) specimens are given in Figure 2. It can be seen that the FCGR in the welded specimens were significantly higher than that in the parent material at $\Delta K$ of 6 and $11 \mathrm{MPa} \sqrt{\mathrm{m}}$. However, at a $\Delta K$ of $15 \mathrm{MPa} \sqrt{\mathrm{m}}$ the FCGR is close to the rate in the parent material. The fatigue crack growth rate (FCGR) curves from the $\mathrm{C}(\mathrm{T})$ specimen can be seen in Figure 3. The C(T) samples were first tested at $\Delta K$ of $11 \mathrm{MPa} \sqrt{\mathrm{m}}$ but crack arrest occurred as the crack approached the weld line. The load was therefore increased to $\Delta K=13$ $\mathrm{MPa} \sqrt{\mathrm{m}}$ and the crack grew slowly before crack arrest occurred again. The applied stress intensity range was then increased further to $15 \mathrm{MPa} \sqrt{\mathrm{m}}$ and the crack then grew through the entire specimen. It can be seen that the rate in the C(T) specimen tested at $\Delta K$ of $15 \mathrm{MPa} \sqrt{\mathrm{m}}$ is even lower than the rate in the $\mathrm{M}(\mathrm{T})$ specimen tested at $\Delta K$ of $6 \mathrm{MPa} \sqrt{\mathrm{m}}$.

The crack-opening stress intensity factor $\left(K_{\mathrm{op}}\right)$ for the $\mathrm{M}(\mathrm{T})$ and $\mathrm{C}(\mathrm{T})$ specimens is shown in Figure 4. The result for the parent plate of 2024 tested at $\Delta K=11 \mathrm{MPa} \sqrt{\mathrm{m}}$ is also shown. It can be seen that the crack opening stress intensity factor is constant for the $\mathrm{M}(\mathrm{T})$ specimen tested at a $\Delta K=6 \mathrm{MPa} \sqrt{\mathrm{m}}$ whereas it fluctuates significantly for another $\mathrm{M}(\mathrm{T})$ specimen tested at a $\Delta K=11$ $\mathrm{MPa} \sqrt{ } \mathrm{m}$. It can also be seen that the $K_{\mathrm{op}}$ values are greater than that of the parent material for the latter specimen. This is not consistent with the observed crack growth rates where the rate in the welded sample was faster than in the parent plate (Figure 2). For the $\mathrm{M}(\mathrm{T})$ specimen tested at $\Delta K$ $=15 \mathrm{MPa} \sqrt{\mathrm{m}}$, the $K_{\text {op }}$ decreased with crack length. This is reflected in the FCGR for this specimen (Figure 2). For the $\mathrm{C}(\mathrm{T})$ specimen, a large crack opening stress intensity factor was seen. This is consistent with the low FCGR found in the specimen tested at a $\Delta K=15 \mathrm{MPa} \sqrt{\mathrm{m}}$ and the crack arrest that occurred for the $\mathrm{C}(\mathrm{T})$ specimens tested below this load level.

The measured residual stresses in the $\mathrm{M}(\mathrm{T})$ specimen, un-fatigued condition and at a crack length of $12 \mathrm{~mm}$, are shown in Figure 5. It can be seen that the residual stresses re-distribute as a result of the crack growth and that the peak stresses are higher after crack growth than in the uncracked condition. Measurements were also made at the minimum and maximum loads in the fatigue cycle for some crack lengths and these measurements showed [6] that the measured compressive residual stress field in the wake of the crack for the $M(T)$ specimen (Figure 5) was independent of applied load and so cannot be due to physical crack closure. Tsakalakos et al. [17] and Croft et al. [18] have measured the residual strain within a single overloaded C(T) specimen using energy 
dispersive synchrotron X-ray diffraction. They also found an apparent compressive stress in the wake of the crack even after the specimen was completely fractured; hence again there is no physical closure. Compressive macro-stresses can be ruled out as the crack plane must be a traction-free surface. These authors suggested that these apparent stresses may be due to anisotropic plastic strains in the crack wake [18] or measurement error due to the gauge volume differing in the two measured directions [17]. Another reason for the apparent compressive residual stress field is that plane stress was used in the computation of the stresses in this work. This is not necessarily the case for a residual stress field, even in a relatively thin plate, and this may have introduced systematic errors in the stress computation.

The residual stress distribution in the $\mathrm{C}(\mathrm{T})$ specimen in the un-fatigued condition and after 29 $\mathrm{mm}$ of fatigue crack growth is shown in Figure 6. The initial residual stresses can be seen to be significantly smaller than that observed in the $\mathrm{M}(\mathrm{T})$ specimen. Furthermore, it can be seen that due to the notch machined into this specimen the stress field is asymmetric and, in contrast to the $\mathrm{M}(\mathrm{T})$ results, the (compressive) residual stresses near the initial crack tip were little affected by crack growth until the crack tip had grown through the initial compressive residual stress field at about $10 \mathrm{~mm}$ from the weld centre [7].

The residual stress measurements do indeed reflect the fatigue crack growth behaviour in the samples where a faster growth rate in generally was observed in the $\mathrm{M}(\mathrm{T})$ sample and a slower rate in the $\mathrm{C}(\mathrm{T})$ sample compared with the parent material.

The resulting residual stresses using both the SIGINI subroutine and the eigenstrain approaches are shown for the $\mathrm{M}(\mathrm{T})$ sample in Figure 5. There is a good correlation between the two sets of FE results and the measured data, which also indicates that the measured residual stresses were balanced.

The resulting elastic strain distribution in the $\mathrm{C}(\mathrm{T})$ specimen is compared with the experimental results in Figure 7. The predicted elastic strain distribution from the eigenstrain distribution in the $\mathrm{M}(\mathrm{T})$ specimen was in excellent agreement with the experimental results. This verifies the assumption of a continuously processed body.

The predicted residual stresses (using the initial stresses or eigenstrain distribution in the uncracked $\mathrm{M}(\mathrm{T})$ ) in un-fatigued and at $29 \mathrm{~mm}$ fatigue crack growth for the CT specimen are shown in 6 . The predicted elastic re-distribution with crack growth was hence in reasonably good correlation with the experimental results for both specimen configurations and it can therefore be concluded that to a first approximation, the evolution of weld residual stresses is principally governed by elastic re-distribution [6,7].

The predicted results for the $\mathrm{M}(\mathrm{T})$ are compared with the experimental results in Figure 2a (crack closure approach) and Figure $2 \mathrm{~b}$ (residual stress approach). For the crack closure approach the results were highly non-conservative for the lower stress intensity factor range, but a good prediction was obtained at $\Delta K=15$, and an excellent prediction of the rate in the parent plate tested at $\Delta K=11$ was found. There was a good correlation between the experimental results using the residual stress approach for $\Delta K=6$ and 11. For $\Delta K=15$ the prediction was conservative, as the rate in this case was not significantly accelerated compared with the parent plate.

The predicted rates for the $\mathrm{C}(\mathrm{T})$ specimen (Figure 3) at the lower stress intensity ranges were in reasonable correlation with the experimental results using the residual stress approach. Excellent prediction was found for the specimen tested at $\Delta K=15$. A reasonable prediction was also found for this case using the crack closure approach. 
The two approaches to crack growth rate prediction are largely equivalent, as the crack growth rates derived using the $K_{\text {res }}$ technique are those predicted by the NASGRO equation for the local crack tip $R$-ratio. The equation constants and its form are based on experimentally-measured crack growth data for parent 2024 plate at different mean stresses. In turn, these measured growth rates reflect the effects of crack closure and other parameters operating in those test conditions. The crack closure behaviour is of course measured directly in the $\Delta K_{\text {eff }}$ approach and is used to calculate the resultant growth rate. The $K_{\text {res }}$ approach has the advantage that it will reflect the possible influence of $R$-ratio parameters influencing crack growth rates which are not associated with crack closure.

\section{CONCLUDING REMARKS}

1. The initial residual stresses in a welded plate were found to re-distribute with crack growth in $\mathrm{M}(\mathrm{T})$ and $\mathrm{C}(\mathrm{T})$ fatigue specimens.

2. The initial residual stress distributions in the $\mathrm{M}(\mathrm{T})$ and $\mathrm{C}(\mathrm{T})$ specimens are very different. The residual stresses accelerated the fatigue crack growth rate in the $\mathrm{M}(\mathrm{T})$ specimen whereas they decelerated the growth rate in the $\mathrm{C}(\mathrm{T})$ sample. Thus, fatigue crack growth rates obtained from laboratory specimens, of which the exact residual stress field is not known, may be misleading. It is critical that such factors are taken into account when designing damage tolerant aerospace structures based on laboratory specimen data.

3. The effect of the residual stress on the $R$-ratio and $\Delta K_{\text {eff }}$ was computed for both specimen geometries using the residual stress and crack closure approaches. The calculated stress intensity factor range or effective stress intensity factor range was then used to predict the fatigue crack growth rate employing an empirical fatigue crack growth law. The predicted FCGR in the welded $\mathrm{M}(\mathrm{T})$ specimens agreed well with the tests conducted at the lower load levels using the residual stress approach. There was however a dip in the experimental FCGR data at about $10 \mathrm{~mm}$ which was not predicted by the model. This might be due the micro structural changes in the transition between the HAZ and the parent material (Figure 8) which are not included in the model at this time. The largest discrepancy between the experimental results and the predictions was found for the $\mathrm{M}(\mathrm{T})$ specimen at lower loads using the crack closure approach. For an open crack or a very small closure the output from the eddy current transduced might give misleading results as any non-linearity might be interpreted as crack opening. At the highest loads, a conservative prediction was obtained using the residual stress approach. This might be due to significant residual stress relaxation caused by gross plastic effects at this level of load. A good prediction was in this case obtained using the crack closure approach. For the $\mathrm{C}(\mathrm{T})$ specimen, both the experimental results and both sets of predictions were in good agreement. To obtain better agreement, models that incorporate both residual stress and crack closure methods may be needed.

\section{REFERENCES}

[1] UK DTI Aerospace innovation growth team report June 2003.

[2] J.F. Throop and H.S Reemsnyder, ASTM 04-776000-30, 1981.

[3] M.E. Fitzpatrick and L. Edwards, "Fatigue Crack / Residual Stress Field Interactions and their Implications for Damage Tolerant Design”, J. Mat. Eng. \& Perf., 7, 190-198 (1998) 
[4] L. Edwards, M.E. Fitzpatrick, P.E. Irving, I. Sinclair, X. Zhang and D. Yapp, “An integrated approach to the determination and consequences of residual stress on the fatigue performance of welded aircraft structures", J. ASTM Int., 3, JAI12547, doi: 10.1520/JAI12547 (2006).

[5] J. Brouard, J. Lin J and PE Irving, "Effects of residual stress and fatigue crack closure during fatigue crack growth in welded 2024 aluminium", Proceedings of Fatigue 2006, Atlanta, USA, June 2006.

[6] C.D.M. Liljedahl, J.F. Tan, O. Zanellato, S. Ganguly, M.E. Fitzpatrick and L. Edwards, "Evolution of residual stresses with fatigue loading and subsequent crack growth in welded aluminium alloy middle tension specimen", Eng. Fract. Mech, In Press

[7] C.D.M. Liljedahl, O. Zanellato, L. Edwards and M.E. Fitzpatrick, "Evolution of residual stresses with fatigue crack growth in a VPPA-welded aluminium alloy compact tension specimen”, Metall. Mater. Trans. A, Submitted.

[8] C.D.M. Liljedahl, J.F. Tan, L. Edwards and M.E. Fitzpatrick, "The effect of residual stress on fatigue crack growth rate in standard test samples sectioned from a VPPA-welded aluminium plate", Theor. Appl. Fract. Mech., Submitted.

[9] Santisteban, JR, Daymond MR, James JA and Edwards L, "ENGIN-X: a third generation neutron strain scanner", J. Appl. Cryst., 39, 812-825 (2006).

[10] ABAQUS Version 6.5, Hibbitt, Karlsson \& Sorensen, Inc., 2005.

[11] M.R. Hill, Modelling of residual stress effects using eigenstrain, 10th International Conference on Fracture, Oahu, Hawaii, December 2001.

[12] A.T. DeWald and M.R. Hill, Multi-axial contour method for mapping residual stresses in continuously processes bodies, Exp. Mech., 46, 473-490 (2006).

[13] W. Elber, The significance of fatigue crack closure, in Damage Tolerance in Aircraft Structures, ASTM STP, 486, 230-242 (1971).

[14] P. Parker, Linear elatic fracture mechanics and fatigue crack growth - residual stress effects, Sagamore Army Materials Research Conference proceedings, 1982.

[15] J. Rice, A path independent integral and approximate analysis of strain concentration and cracks, J. Appl. Mech., 35, 379-387 (1968).

[16] J.A. Harter, AFGROW Users Guide and Technical Manual, AFRL-VA-WP-TR-2004, 2004.

[17] T. Tsakalakos, M.C. Croft, N.M. Jisrawi, R.L. Holtz and Z. Zhong, Measurment of residual stress distributions by energy dispersive X-ray diffraction syncrotron radiation, Internacional Offshore and Polar Engineering Conference, San Francisco, California, USA, May 2006.

[18] M. Croft, Z. Zhong, N. Jisrawi, I. Zakharchenko, R.L. Holtz, J. Skaritka, T. Fast, K. Sadananda, M. Lakshimpathy and T. Tsakalakos, Strain profiling of fatigue crack overload effects using energy dispersive X-ray diffraction, Int. J. Fatigue, 27, 1408-1419 (2005). 


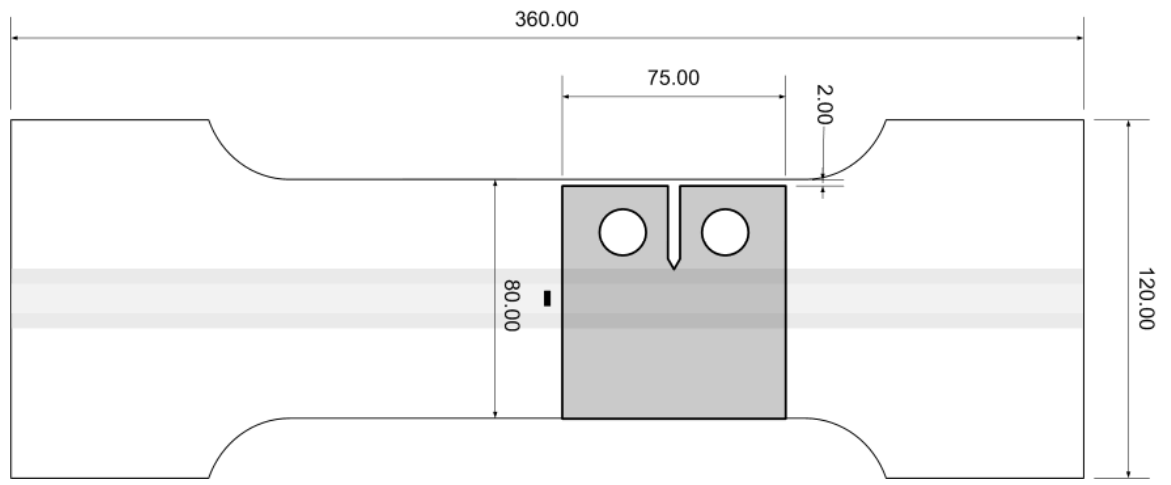

Figure 1 Geometry for the $\mathrm{M}(\mathrm{T})$ and $\mathrm{C}(\mathrm{T})$ specimen (the grey regions represent the weld bead).

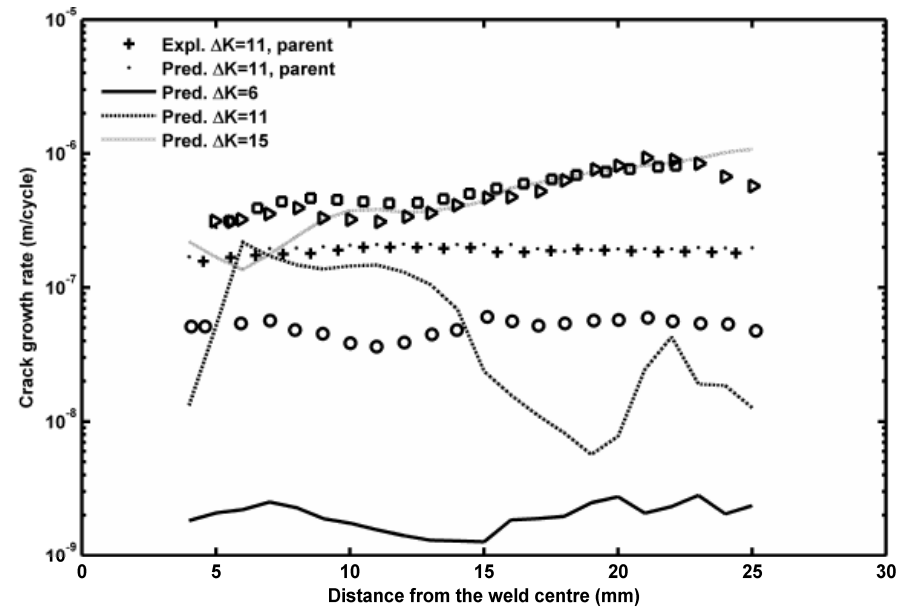

Fig. 2a) using the crack closure approach

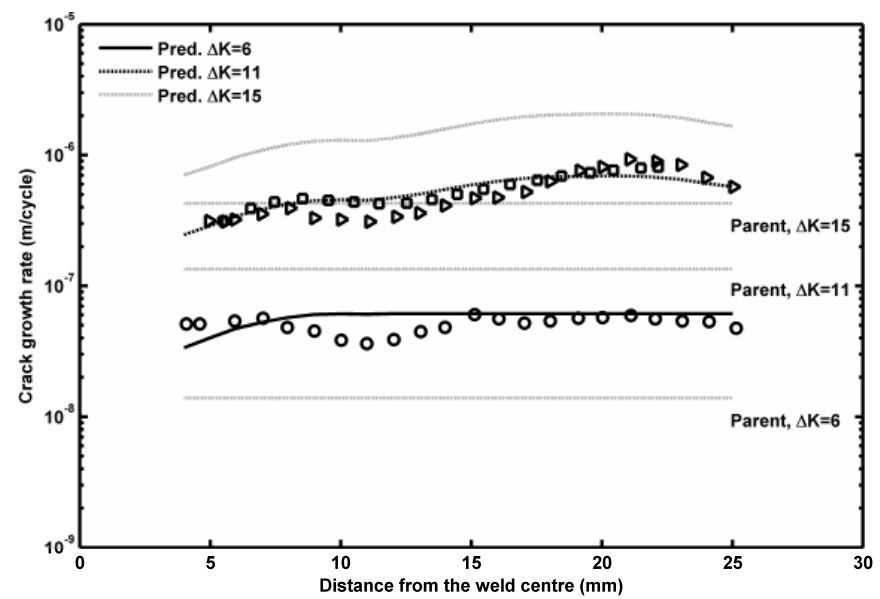

Fig 2b) using the residual stress approach

Figure 2 Experimental results and predictions of the crack growth rate in the welded $\mathrm{M}(\mathrm{T})$ specimen (applied load: $\mathrm{R}=0.1, \circ \Delta \mathrm{K}=6, \Delta \mathrm{K}=11, \square \Delta \mathrm{K}=13$ ) 


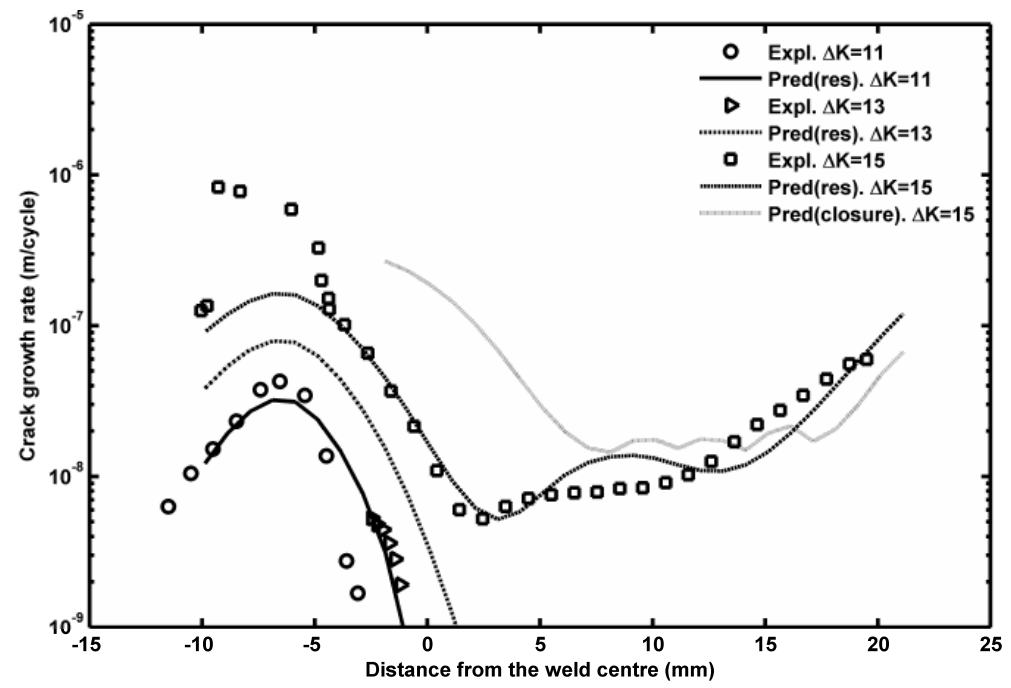

Figure 3 Experimental and numerical results of the crack growth rate in the $C(T)$ specimen $(\mathrm{R}=0.1$, closure - predictions using the crack closure approach, res - predictions using the residual stress approach)

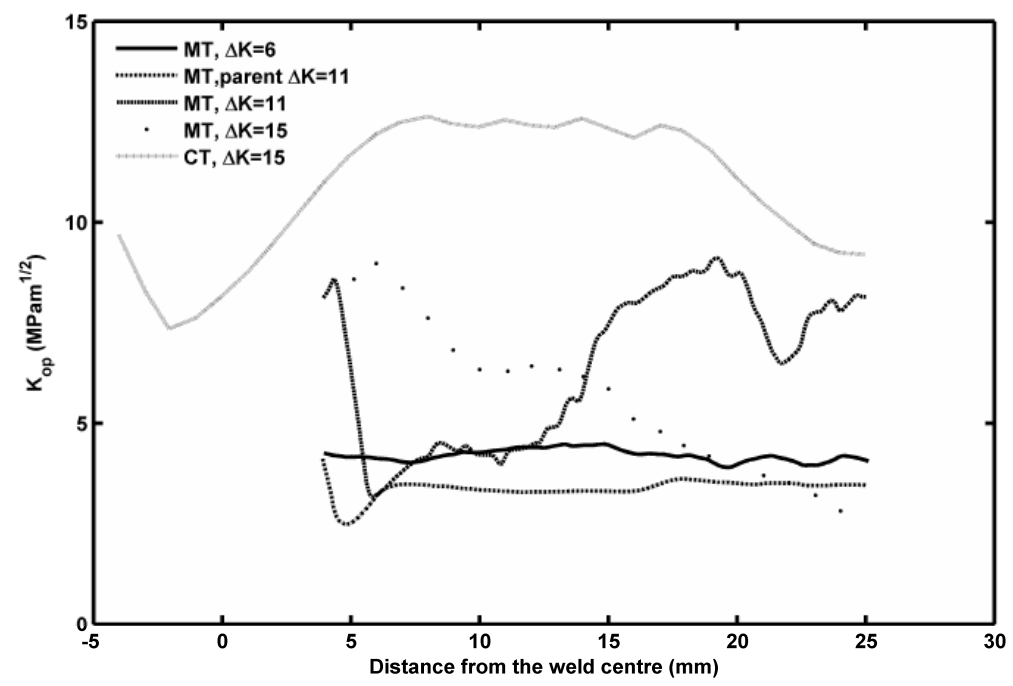

Figure 4 Measured crack opening stress intensity factor for $M(T)$ and $C(T)$ specimen $(R=0.1)$ 


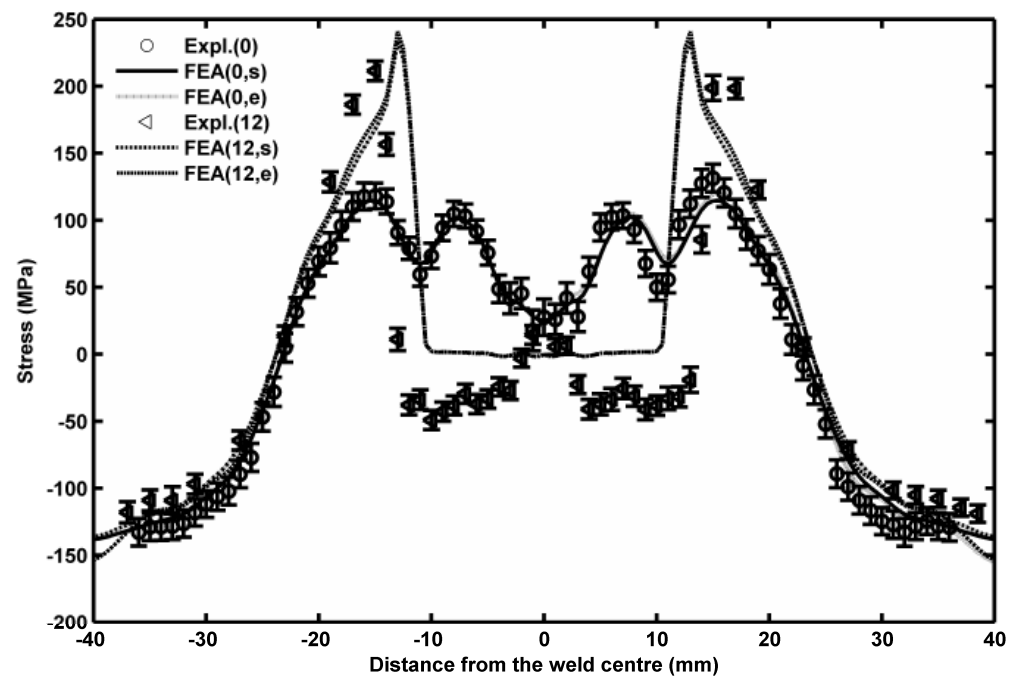

Figure 5 Experimentally determined and predicted residual stresses in the longitudinal direction ( $\mathrm{s}$ - using the SIGINI subroutine and $\mathrm{e}$ - using the eigen-strain approach) in the $\mathrm{M}(\mathrm{T})$ specimen in un-fatigued condition ( $\odot$ ) and after $12 \mathrm{~mm}(\square)$ crack growth)

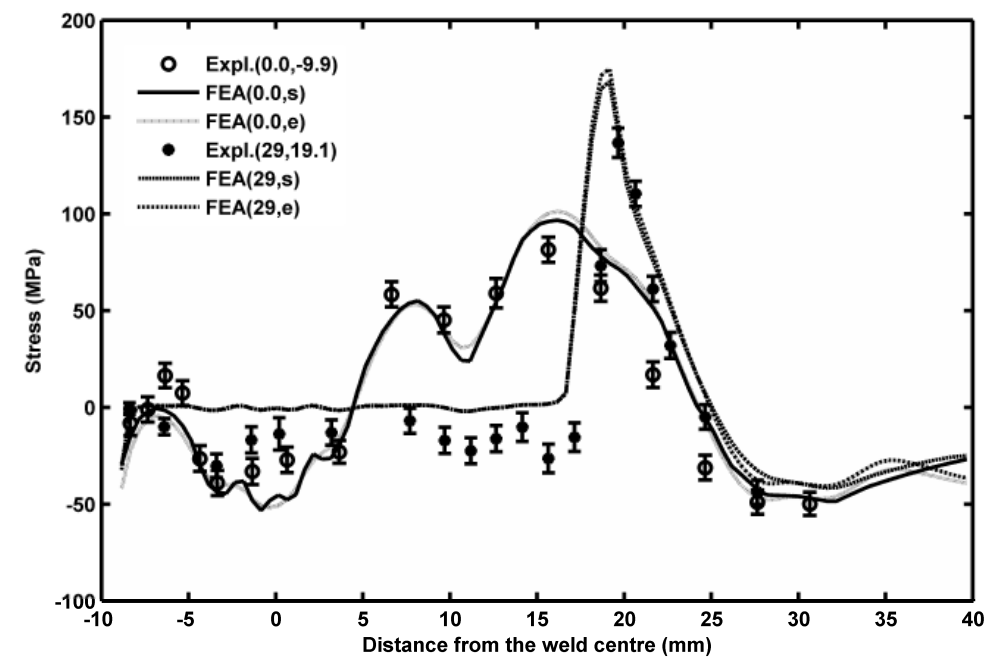

Figure 6 Experimentally determined and predicted residual stresses in the longitudinal direction in the $\mathrm{C}(\mathrm{T})$ specimen in un-fatigued condition $(\circ)$ and at $29 \mathrm{~mm}(\square)$ fatigued crack length (the first number in the legend refers to the fatigued crack length and the second number refers to the distance of the current crack tip position to the weld centre). 


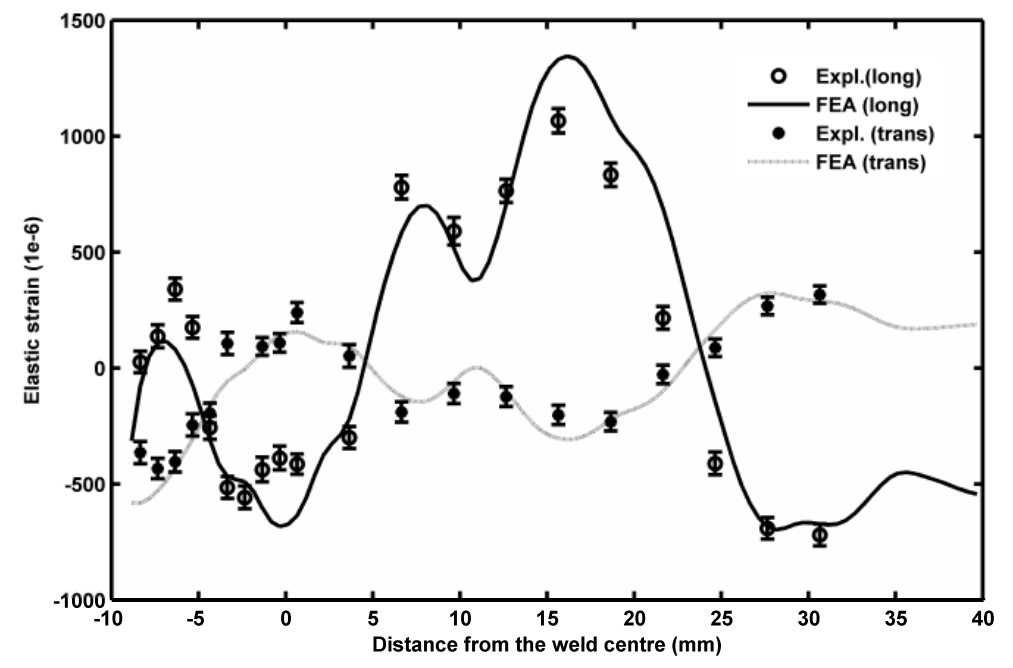

Figure 7 Experimentally determined and predicted residual elastic strains in the $\mathrm{C}(\mathrm{T})$ specimen from the eigenstrain distribution in the $\mathrm{M}(\mathrm{T})$ specimen (in un-fatigued condition)

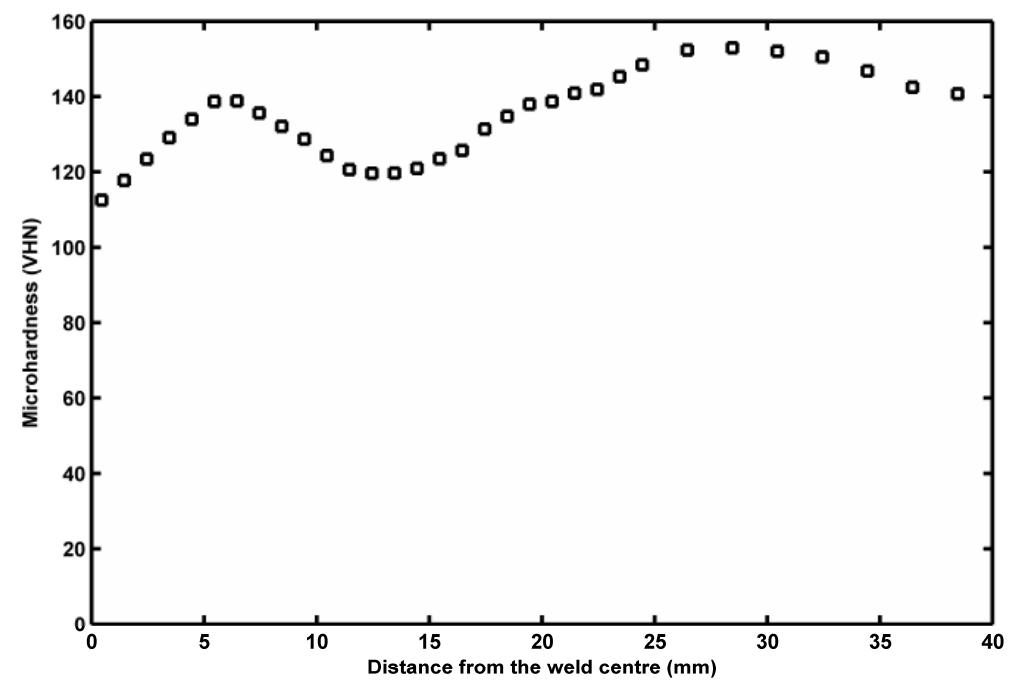

Figure 8 Micro-hardness measured across the weld and the parent material with a Vickers indenter 